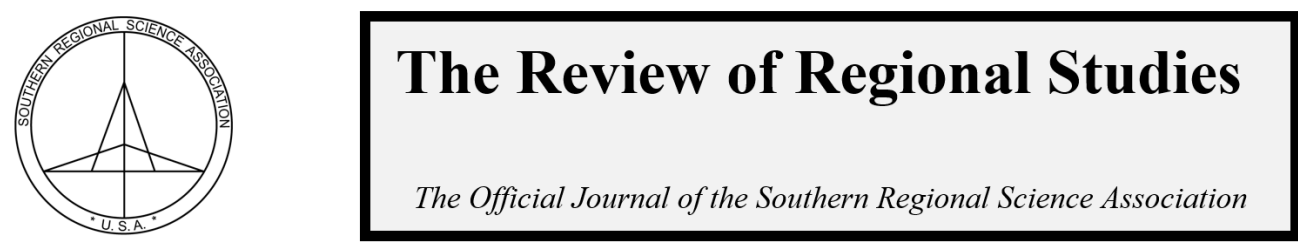

\title{
The Rust Belt, the Sunbelt, and the Concentration of Poverty Within Large U.S. Cities*
}

\author{
Scott W. Hegerty \\ Department of Economics, Northeastern Illinois University, USA
}

\begin{abstract}
Previous research that has quantified the dispersion of U.S. urban poverty has often focused on metropolitan areas rather than on central cities themselves. Detroit, for example, shares a region with wealthy suburbs and thus appears to have concentrated poverty, but the city itself is uniformly poor and has few pockets of wealth. This study calculates four measures of household poverty concentration across block groups inside 74 U.S. cities, finding poor "Rust Belt" cities such as Detroit to have "diffuse" poverty. We also isolate a group of low-poverty, high-concentration cities in the U.S. South and West, as well as outliers that include "Sunbelt" cities with more diffuse poverty than predicted. Regression analysis finds the poverty rate itself to explain most of the variation in poverty concentration, with ethnic composition and the share of service employment also playing a potential role. Calculating changes in tract level poverty distributions from 2010 to 2015, we find that the concentration of poverty has decreased overall and that growth in the share of Hispanic residents might help explain these decreases.
\end{abstract}

Keywords: urban poverty, concentration, United States, inequality, spatial statistics

JEL Codes: I32

\section{INTRODUCTION}

The widening concentration of poverty in the United States, particularly in large urban centers, has long been a concern to researchers and policymakers alike. But while there have been numerous studies examining the U.S. and other countries, most have addressed metropolitan areas rather than city centers themselves. For this reason, their findings have mainly uncovered significant urban-suburban inequalities. Rusk (2013), for example, finds the Detroit metro area to be among the most segregated in the U.S.

An examination of the city itself, not including any suburbs, shows a different distribution, however. Within Detroit, poverty is more evenly spread out inside its urban boundaries than in many other cities. Chicago, for example, has high-poverty neighborhoods on its West

\footnotetext{
${ }^{*}$ The helpful comments of Dr. Patricia Smith and other participants at the 2018 Midwest Economics Association meeting, as well as those of two anonymous referees, are greatly appreciated.

Hegerty is an Associate Professor of Economics at Northeastern Illinois University, 5500 N. Saint Louis Ave., Chicago, IL 60625. E-mail: S-Hegerty@neiu.edu
} 
and South Sides, but includes both wealthy areas on the North Side (near Lake Michigan) and middle-class neighborhoods to the Northwest and Southwest. Policymakers and pundits sometimes make comparisons between the two cities (and between Detroit and other urban centers), when the reality is actually quite different. Wealthy neighborhoods can subsidize poor ones, so that a less evenly poor city can avoid Detroit's fate of drastically reduced public services. It is therefore necessary to establish a metric for the concentration of urban poverty, so that policies that might be beneficial for Detroit can be applied in the appropriate context. Similar cities can also be identified, as well as cities that might be quite different in their poverty distributions. These metrics can then inform urban policy.

Concentrated poverty, as Sharkey $(2008,2012)$ notes, is resilient, even in the face of residential mobility. As the vast literature on "neighborhood effects" highlights, the geographic distribution of poverty can have a direct impact on health and other outcomes. Small and Newman (2001) discuss some of the mechanisms through which poverty affects quality of life; specific effects include mental health (Leventhal and Brooks-Gunn, 2003) as well as reduced educational opportunities, wealth, and private investment and increased crime and costs of government (Kneebone et al., 2011). Yet, as noted above, empirical studies often focus on MSAs rather than specifically on urban cores. Some earlier examples, which model the concentration of urban poverty and differences among socioeconomic groups, include Madden (1996), Adelman and Jaret (1999), and Madden (2003). More recently, Aliprantis et al. (2013) calculate Gini coefficients for large MSAs and find Rust Belt cities such as Milwaukee and Detroit to have highly concentrated poverty.

Other studies incorporate a more varied mix of geographical areas. Examples include Dawkins (2004), who calculates a set of Gini coefficients specifically for the city of Atlanta; Cook and Marchant (2006), who find increased poverty in Northeastern urban cores and the inner-ring suburbs of growing Sunbelt regions; Weinberg (2011), who discovers a negative relationship between Gini coefficients and household income in states and metros of various sizes; and Howell and Timberlake (2014), who examine time trends and racial disparities in suburban poverty. Rusk (2013) notes that "elastic" cities, which have been able to incorporate and annex neighboring suburban areas, have lower concentrations of poverty than "inelastic" cities in the Northeast and Midwest. Most relevant to the current study, Ades and Apparicio (2012) construct a number of measures, based on earlier work by Massey and Denton (1988), for eight large Canadian metro areas and evaluate changes in these measures over five-year periods. Dwyer (2012) calculates segregation measures during the 1990s, during which poverty had become less concentrated, and Kavanagh et al. (2016) evaluate changes in poverty concentrations in four Scottish cities between 2001 and 2011.

We seek to expand the use of statistical methods for a large sample of central cities, so that we may examine underlying differences between older cities such as Detroit and fastergrowing places that still experience considerable poverty. We do so for a set of more than 70 large U.S. cities, analyzing the cities themselves rather than their surrounding metropolitan areas. We focus on four main goals: 1) Measuring the distribution of poverty by calculating and comparing four separate statistics; 2) finding relevant socioeconomic variables that explain variations in the distribution of poverty among cities; 3) describing and attempting to explain changes in these distributions; and 4) noting avenues for future research, particularly for "outlier" cities with unexpectedly concentrated or "diffuse" poverty.

(C)Southern Regional Science Association 2019. 
Overall, we find that our main block-group-based concentration measures are most closely related to the poverty rate itself, with explanatory variables such as population, its change, and city elasticity having little significant effect. Ethnic composition (particularly the share of White and Hispanic residents), as well as the share of service (but not professional) employment, also contribute in many cases. We note differences in the poverty distributions of Detroit and other "Rust Belt" cities, especially when compared to booming cities such as Plano (Tex.), and find outliers that may warrant further analysis. Tract-based poverty concentration mostly decreases from 2010 to 2015, but this seems not to be explained by any economic characteristics.

This paper proceeds as follows. Section 2 discusses a theory of poverty diffusion, while Section 3 outlines the paper's methodology. Section 4 describes the results and Section 5 concludes, highlighting three key avenues for further research.

\section{A BASIC THEORY OF POVERTY DIFFUSION}

While this study is primarily empirical, we begin with a simple theoretical framework to explain both the diffusion process within cities and differences between cities. First, we expect that, all else equal, high poverty cities will have higher dispersions of residents in poverty. One way to visualize this is to borrow a science example and imagine the diffusion of a gas in a jar: a large number of atoms will fill the available space evenly due the transfer of energy. Here, however, the diffusion process is based on economic forces and poverty is contained by city borders, where tax and other policies differ (and where other, less benign, tactics are sometimes employed).

A hypothetical city with 1,000 people and five neighborhoods, for example, could have a 40 percent poverty rate and high segregation if all 400 poor residents lived in one neighborhood and 150 non-poor residents lived in each of the other four neighborhoods. But we would expect poverty to spread across the borders between the rich and poor areas and poverty rates to therefore equalize over time. Poor neighborhoods would drive down nearby property values to the point where low income residents can afford to leave their old neighborhoods and move to these more desirable areas. This process would proceed as long as these differentials existed, but city borders (such as the well-known example of Detroit's Eight Mile Road) might provide a sufficiently powerful boundary and thus contain poverty. While positive changes in the other direction are possible, their effects are limited. Gentrification, which is currently taking place in Detroit and elsewhere, might only take place in certain areas within the city and be insufficiently large-scale to lower the dispersion of poverty overall.

We also expect that national and international economic forces, and particularly industrial decline, will play a large role in regional differences in the dispersion of U.S. urban poverty. Since a plant closing will be detrimental to a large surrounding area, we expect its effects to be concentrated in entire cities in the Northeast and Midwest. Even outmigration by residents could leave the "poorest of the poor" behind. This contributes to the dispersion of poverty if the most relatively well-off leave for better neighborhoods.

In addition, many "Rust Belt" cities also are surrounded by incorporated suburbs and

(C)Southern Regional Science Association 2019. 
therefore contain a larger proportion of high-density "core" areas than cities in the South and West. A high-poverty neighborhood in a more elastic city could be surrounded by suburblike areas that would be part of a separate city elsewhere, so this type of "overbounded" city would appear to have a higher concentration of poverty, all else equal. Racial and ethnic factors can also play a key role in distributions of poverty. Housing policy has long helped to restrict African-Americans to central cities. The corresponding outmigration of Whites has led to wide urban-suburban divergences in the Northeast and Midwest. Immigration, often from Mexico, could lead to both population growth and changes in incomes, so "Sunbelt" cities and others in the South and West might exhibit differing distributions of nonwhite populations than do "Rust Belt" cities. We can test these theories, for all regions, in our empirical analysis.

\section{EMPIRICAL METHODOLOGY}

Data for this study come from the U.S. Census American Community Survey (ACS). We use 2014 data (5-year estimates) at the block-group level and 2010 and 2015 ACS data at the tract level. We also use population data for Census-designated places, basing our evaluation only on the 77 cities which have a 2014 population estimate of 250,000 or greater. Not only does this threshold represent a common definition of "large" cities, it also balances a sufficiently large sample size with a sufficient number of block groups within each city. Because some of these cities might be contiguous (such as Minneapolis-St. Paul, or major cities with large suburbs), we examine visually whether any pairs or groups share a poverty "cluster" across city borders. In three cases, we treat two cities together, while in others, we leave them separate. ${ }^{1}$

Using data for a total of 74 major cities (including three city pairs), we calculate four metrics to capture the concentration of poverty. First, we calculate the Gini coefficient based on five groups of roughly equal numbers of households. Next, following Massey and Denton (1988), Ades and Apparicio (2012), and others, we also include two nonspatial indices and one spatial measure of poverty concentration. These are the Isolation Index $(I S)$, the Exposure Index $(x P X)$, and the Absolute Concentration Index $(A C O)$. These measures all take values between zero and one, and generally compare each block group's share of the city's total households in poverty with its percentages of households not in poverty or its overall share of total population. The $A C O$ measure also includes land area in its calculation.

Our four measures are as follows:

1. The Gini coefficient is calculated by placing tracts, in order of increasing poverty rates, into five groups of equal population size. Cumulative proportions of households in poverty for each quintile form a Lorenz curve (see Figure 1), which is compared against a 45-degree line and the triangle below using simple geometry. A value of zero represents perfectly distributed poverty and a value of one represents perfectly concentrated poverty. The bestknown of the four measures used here, it is commonly found in country studies of economic

\footnotetext{
${ }^{1}$ These are: Los Angeles/Long Beach, CA; Denver/Aurora, CO; and San Diego/Chula Vista, CA. At the same time, Dallas, Ft. Worth, and Arlington (TX), as well as Minneapolis and St. Paul, MN (among others), are evaluated individually.
}

(C)Southern Regional Science Association 2019. 
development (where a value of one implies that one person has all of a country's income and a value of zero represents perfect income equality).

2. The Isolation Index, which uses the number of households in poverty $\left(x_{i}\right)$ and population $\left(t_{i}\right)$, with $X$ and $T$ representing citywide totals of each group:

$$
I S=\frac{1}{2} \sum_{i=1}^{n}\left|\frac{x_{i}}{X}-\frac{t_{1}-x_{i}}{T-X}\right|
$$

Conceptually, this score is made up of the difference of two components and concentration rises if constituent block groups or tracts contain large shares of the total number of households in poverty (the left part of the difference) or large shares of the total number of households not in poverty (the absolute value of the right part).

3. The Exposure Index, which interacts each block group's or tract's poverty rate with its percentage of the city's total number of households in poverty:

$$
x P x=\sum_{i=1}^{n}\left[\frac{x_{i}}{X}\right]\left[\frac{x_{i}}{t_{i}}\right]
$$

This score, being the sum of two products, increases if its constituent areas both have large shares of the total number of households in poverty and have high poverty rates. Since it is difficult for many constituent block groups or tracts to have both if poverty is concentrated, high scores represent more diffuse poverty.

4. The Absolute Concentration score, which compares the land area taken up by households in poverty versus the total population. Here, households are sorted by population and divided into groups with a breakpoint where the cumulative population equals $X$. This is done both from the smallest to largest $\left(n_{1}\right)$ and from largest to smallest $\left(n_{2}\right) . T_{1}$ is the cumulative population sum from 1 to $n_{1}$ and $T_{2}$ is this sum from $n_{2}$ to $n$. $A_{i}$ is the land area of each tract:

$$
A C O=1-\frac{\sum_{i=1}^{n} \frac{x_{i} A_{i}}{X}-\sum_{i=1}^{n 1} \frac{t_{i} A_{i}}{T_{1}}}{\sum_{i=n 2}^{n} \frac{t_{i} A_{i}}{T_{2}}-\sum_{i=1}^{n 1} \frac{t_{i} A_{i}}{T_{1}}}
$$

Noting that it subtracts the left-hand-side component, we see that the $A C O$ score decreases (representing more diffuse poverty) if constituent areas have large shares of the total number of households in poverty, in a large land area, relative to their shares of the total population. Because the denominator of this component captures overall population concentration, the $A C O$ score is higher if disproportionately large shares of total poverty, relative to population, can be found in small land areas.

These four measures are conceptually similar to a certain extent. All are constructed to take values between zero and one, and in three cases (all but the $x P X$ score), low values represent diffuse poverty. These measures also exhibit differences from one another. The Gini coefficient as calculated here applies a set number of component subgroups, which can vary from study to study. While five is a common choice, results might be sensitive to the application of a larger number. The calculations of the other scores have their own 
idiosyncrasies as well. Only the $I S$ score compares households in poverty with those not in poverty and only the $A C O$ score incorporates a spatial component. The $x P X$ score stands out for its "opposite" behavior from the others. At the same time, only $x P X$ includes block group- or tract-level poverty rates $\left(x_{i} / t_{i}\right)$.

Because each of these measures includes slightly different component variables, none can be said to be "superior" to the others, and to our knowledge, there is no systematic comparison of the four. Likewise, no "norms," such as appropriate means or standard deviations, are known to exist and the economic interpretation of a one-hundredth-point increase or decrease is also unknown. We therefore estimate all four and note interesting statistical properties and differences among measures as part of our analysis, leaving comparisons for future research.

Based on these four measures, we next examine the relationship between poverty and poverty concentration for our set of 74 U.S. cities. Poverty concentration appears to be closely related to poverty rates and we seek to explain additional causes of variation through regression analysis. After finding population change since 1960 to be insignificant in a baseline regression, we model each concentration measure as a function of various combinations of the following variables: the poverty rate itself; the population in 2014 (to test whether city size affects plays a role on poverty distributions); the percentages of White, Black, and Hispanic residents (expecting that the effects might be opposite in sign; since these variables are shown to be correlated with one another, they are entered separately in additional specifications); the percentages of service and professional jobs in each city (it is expected that the former are lower-paying and might lead to more diffuse poverty, while the latter might encourage "enclaves" or gentrification); and two separate dummy variables, equaling 1 for each of our identified "Rust Belt" and "Sunbelt" cities, respectively. We also include city "elasticity" (increase in land area since 1960) to one of the better-performing models in an eighth specification. This measures a city's ability to expand its borders through annexation. In models using this variable, we only include cities that were among the 100 largest in both 1960 and 2014, leaving a sample of 54 cities for the OLS estimations that include this variable. Since it is difficult to interpret the coefficient estimates in a meaningful way (because point scores are the dependent variable and no known norms exist), we focus on sign and significance to identify the main contributors to the distribution of urban poverty.

Next, we calculate tract-level distributions for all four measures and their changes from 2010 to 2015. Our main focus is to detect overall shifts in the measures (increased concentration or diffusion) over this period. In a set of bivariate analyses, we also compare changes in the $I S$ score against variables representing income and ethnic composition. Overall, except for ethnic makeup, their explanatory power is limited, and few contributors to changes in poverty concentration are identified. We therefore leave a full explanatory model for this and the other three scores to a later project. Our main results are explained below.

(C)Southern Regional Science Association 2019. 


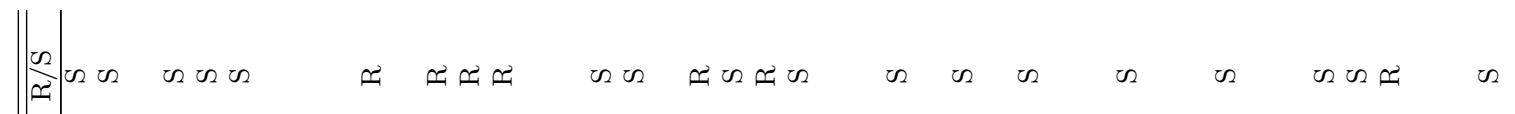

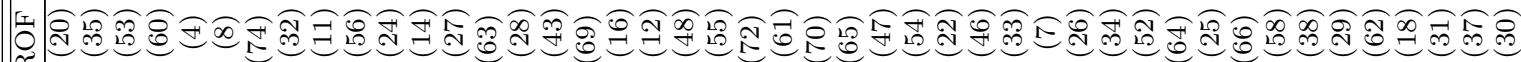
每

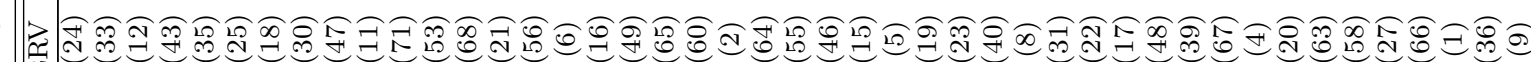
की

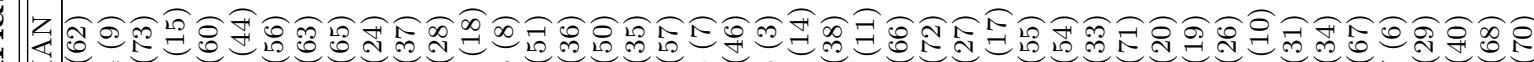

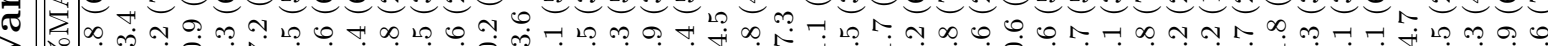

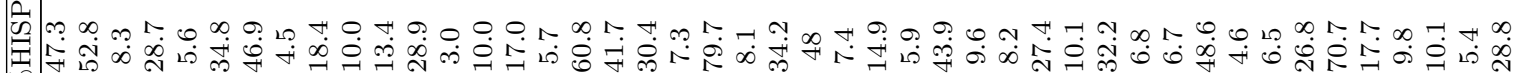

川

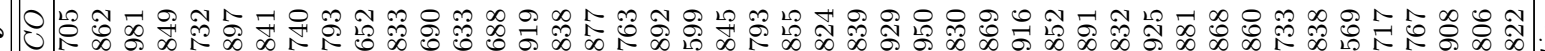

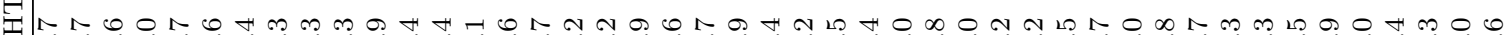

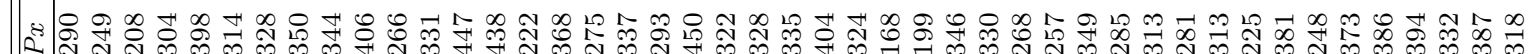

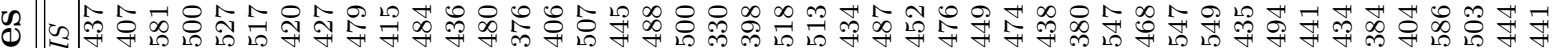

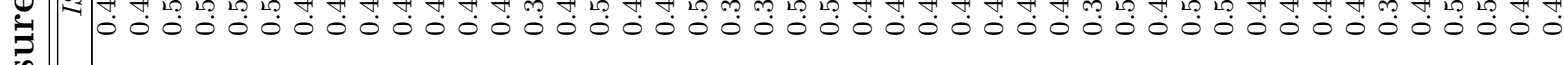

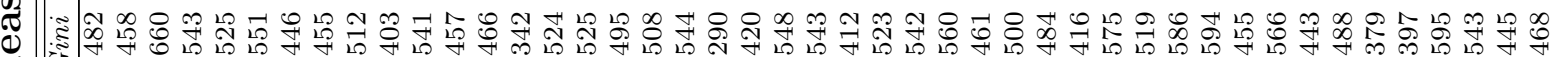

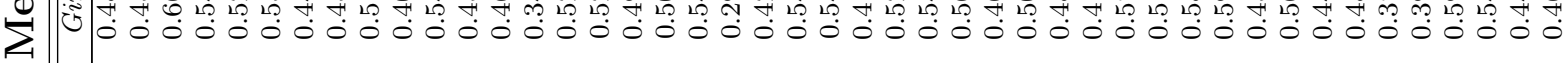

4 L

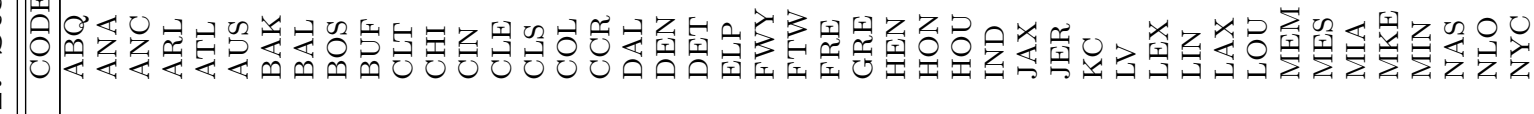

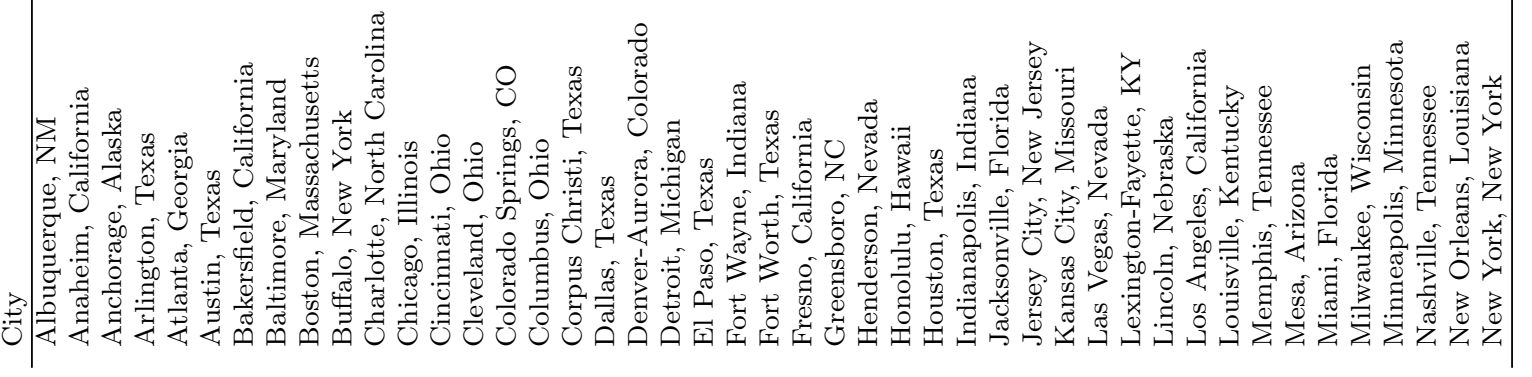

(C)Southern Regional Science Association 2019. 




(c)Southern Regional Science Association 2019. 
Table 2: Spearman Correlation Coefficients

\begin{tabular}{|c|c|c|c|c|c|c|c|c|c|c|c|}
\hline & & & & & A: 2014 & lock-Groul & Measures & & & & \\
\hline Spearman & $I S$ & $x P x$ & $A C O$ & $\% P O V$ & POP2014 & $\% \triangle P O P$ & $\% W H I T E$ & $\% B L A C K$ & \%HISP & \%PROF & \%SERV \\
\hline Gini & 0.890 & -0.483 & 0.503 & -0.817 & 0.036 & 0.216 & 0.398 & -0.280 & -0.337 & 0.272 & -0.702 \\
\hline IS & 1 & -0.162 & 0.315 & -0.559 & 0.071 & 0.082 & 0.288 & -0.071 & -0.392 & 0.238 & -0.660 \\
\hline$x P x$ & & 1 & -0.638 & 0.876 & 0.046 & -0.559 & -0.404 & 0.620 & -0.133 & -0.230 & 0.421 \\
\hline$A C O$ & & & 1 & -0.680 & 0.091 & 0.501 & 0.412 & -0.480 & 0.103 & 0.007 & -0.392 \\
\hline$\% P O V$ & & & & 1 & 0.020 & -0.475 & -0.496 & 0.521 & 0.102 & -0.251 & 0.608 \\
\hline POP2014 & & & & & 1 & 0.051 & -0.069 & 0.026 & 0.229 & 0.280 & -0.104 \\
\hline$\% \triangle P O P$ & & & & & & 1 & 0.481 & -0.629 & 0.483 & 0.021 & -0.275 \\
\hline$\%$ WHITE & & & & & & & 1 & -0.621 & 0.215 & -0.090 & -0.256 \\
\hline$\% H I S P$ & & & & & & & & & 1 & 0.020 & 0.222 \\
\hline$\% P R O F$ & & & & & & & & & & 1 & -0.252 \\
\hline \multicolumn{12}{|c|}{ Bold = high correlation (above 0.6 in absolute value). } \\
\hline \multicolumn{12}{|c|}{ B: Tract-Level Measures of Poverty Concentration } \\
\hline & 2015 & & & & 2010 & & & & Difference & & \\
\hline & IS & $x P x$ & $A C O$ & & IS & $x P x$ & $A C O$ & & $I S$ & $x P x$ & $A C O$ \\
\hline Gini & 0.903 & -0.308 & 0.516 & Gini & 0.898 & -0.360 & 0.545 & Gini & 0.853 & -0.173 & 0.440 \\
\hline IS & 1 & 0.112 & 0.273 & $I S$ & 1 & 0.066 & 0.354 & IS & 1 & 0.208 & 0.282 \\
\hline$x P x$ & & 1 & -0.572 & $x P x$ & & 1 & -0.497 & $x P x$ & & 1 & -0.414 \\
\hline
\end{tabular}

\section{RESULTS}

In order to help understand the relationship between visual and quantitative measures of poverty distribution, we present two examples of cities that are shown below to be on opposite ends of the poverty rate-poverty distribution relationship. Figure 1 shows Detroit, where poverty is pervasive and population decline has been precipitous. Fast-growing Plano (Texas), on the other hand, has a very small percentage of households in poverty, and these are concentrated in only a few block groups. Figure 1 also includes Lorenz curves for both cities. Plano's "bowed-out" shape is expected to result in a higher Gini coefficient than Detroit's curve, which is closer to the 45-degree line. Our calculated Gini coefficients capture these differences in poverty distribution, as do our other measures.

Basic characteristics for each city, as well as the calculated poverty distribution statistics and the 2015 employment shares in manufacturing, the professional sector, and services, are provided in Table 1. Across the sample, about 16.7 percent of households were in poverty in 2014, which is close to the 74 cities' average of percentages. Detroit's nearly 35 percent poverty rate is more than three standard deviations above the mean. The three largest U.S. cities (New York, Chicago, and Los Angeles) have scores only slightly below the mean value. In fact, they rank about 50 among the 74 cities studied here. We also classify eight Midwestern cities as "Rust Belt" (excluding Chicago and the state capitals of Columbus and Indianapolis) and 26 as "Sunbelt." In Table 1, we see that five of the 10 cities with the largest percentages of manufacturing employment (\%MAN) are located in the Rust Belt (versus two in the Sunbelt). Of the 25 cities with the lowest shares, 13 are found in the Sunbelt. Interestingly, Pittsburgh is the only Rust Belt city in this latter group, having almost completely transformed following the demise of its steel industry. We also note cities with high shares of professional jobs; these include Plano, Atlanta, Jersey City, and Seattle, which figure prominently in our analysis below.

Correlations between the individual measures and socioeconomic variables are provided in Table 2. We find the Gini coefficients and $I S$ scores are closely related to one another. The $A C O$ and $x P x$ scores form another correlated pair - the two also have the strongest correlations with population change since 1960. Of the other variables, the share of service 


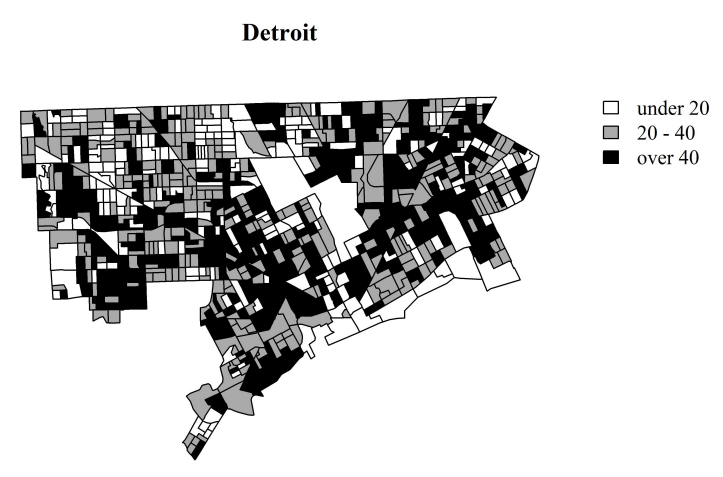

(a) PERCPOV $=34.8 \%$, Gini $=0.290$

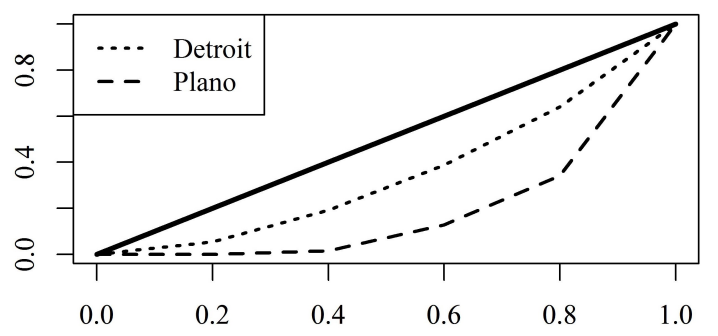

(c) Lorenz Curves
Plano

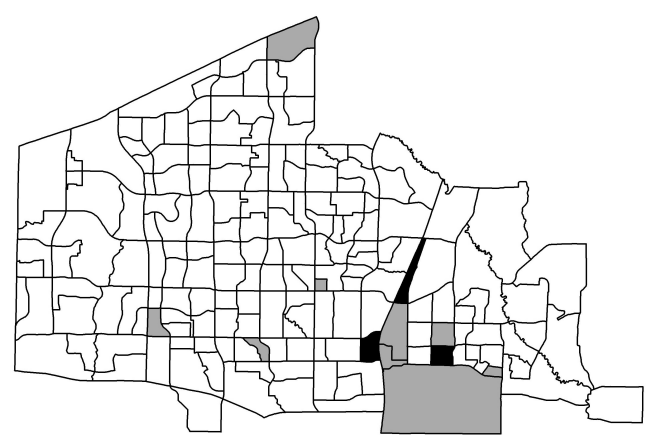

(b) $P E R C P O V=5.4 \%$, Gini $=0.606$

Figure 1: High Poverty/Low Concentration Versus Low Poverty/High Concentration

Lorenz Curves and Gini coefficients: Horizontal axis = Cumulative Percentage of Households in Block Groups; Vertical axis = Cumulative Percentage of Households in Poverty; 45-degree line = Theoretically Even Distribution.

employment exhibits a strong correlation with the poverty rate. This variable is also closely associated with all four concentration measures. The particularly large negative coefficients for the $I S$ score and the Gini coefficient suggest that cities with large service sectors might experience more diffuse poverty, all else equal. As expected, the percentage of White residents is negatively correlated with the percentage of Black residents within the cities in this study. This latter variable is also associated with population loss and with higher poverty rates. The opposite can be said for the percentage of White residents. The percentage of Hispanic residents is associated with population increases and lower poverty concentrations.

The connections between each of the four concentration scores and poverty rates is depicted in the scatterplots of Figure 2. The fit, compared with a bivariate OLS regression line, is particularly tight for the $x P x$ score. For all these graphs, we recognize specific "clusters" on each end of the scatterplot. On one end are high-poverty, low-concentration cities such as Detroit, Newark, and Cleveland. Detroit, in fact, is in a class of its own, having higher and more diffuse poverty than even second place Cleveland. Milwaukee and St. Louis (which, like Newark, can be considered to be a borderline "Rust Belt" city) can be placed into Cleveland's group as well. This stands in contrast to earlier, MSA-level studies, which find Rust Belt cities to have highly concentrated poverty. Although not all cities fall on this end of the distribution (Ft. Wayne [Indiana], for example, lies toward the middle), the 
Gini

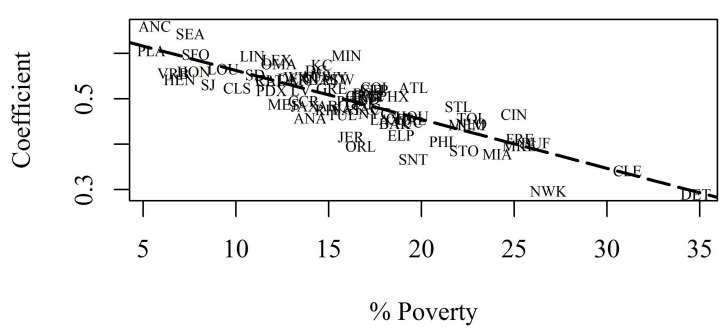

IS

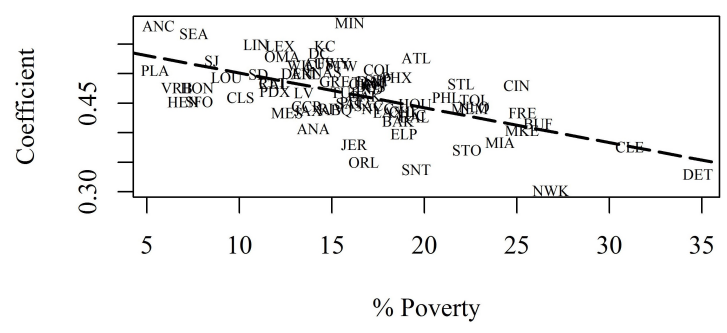

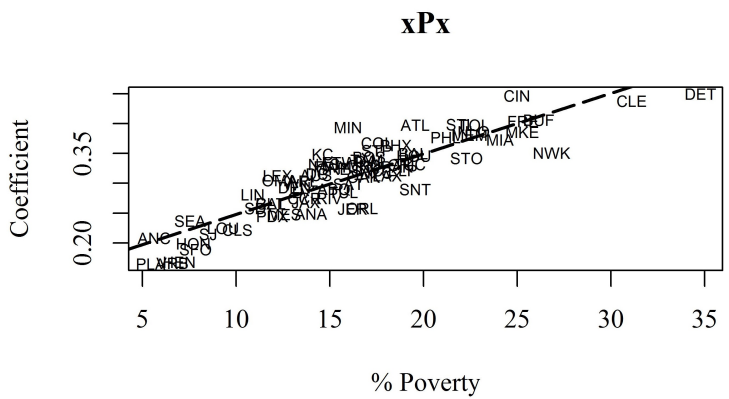

ACO



Figure 2: Poverty Distribution (y-axis) versus Percent Poverty (x-axis), 2014 Measures

largest industrial centers do.

On the other end of the graph are low-poverty, high-concentration growth areas such as Anchorage, Plano, and Henderson (Nevada). These cities have certain unique attributes - one is the hub of the Alaskan economy, one is a wealthy suburb of Dallas, and one lies outside booming Las Vegas - and therefore might represent an elite grouping. The same can be true for technology hubs such as Seattle and San Francisco or the resort city of Virginia Beach. A large share of professional jobs or a unique location might help explain this end of the distribution. Many more "typical" U.S. cities, including the three largest, are clustered in the middle of these distributions near the prediction line. Since high poverty rates closely correspond with low poverty concentrations, the basic theory of poverty diffusion as outlined above appears to be supported.

It is important to note a number of "outliers" that deviate from the expected poverty ratepoverty concentration relationship. Santa Ana (Calif.), for example, has more distributed poverty than expected, since it falls below the regression lines. Perhaps this is due to the city's rapid growth, which is driven in large part by immigration. Unexpectedly diffuse poverty is also found in Orlando, Anaheim, and El Paso, suggesting that the "Sunbelt" may form a unique class of city based on these measures. But there is no unique pattern among all 26 cities in this group. Phoenix, for example, has a lower-than-expected poverty concentration, and Newark's is lower still. But more than a third of the Sunbelt cities primarily the smaller and medium-sized ones - have lower-than-predicted Gini coefficients. Minneapolis and Atlanta, with a number of corporate headquarters and large shares of professional employment, are among the cities with atypically high concentrations. We begin to explain these differences in our regression analysis, and suggest that further research explain what variation remains.

(C)Southern Regional Science Association 2019. 
Table 3: Baseline Regression Results

\begin{tabular}{|c|c|c|c|c|}
\hline 2014 Values & $\overline{\mathrm{DV}: I S}$ & $\overline{\mathrm{DV}}: A C O$ & DV: Gini & \\
\hline Variable & Coeff. (p-val.) & Coeff. (p-val.) & Coeff. (p-val.) & \\
\hline CONSTANT & $0.566(0.000)$ & $1.018(0.000)$ & $0.067(0.000)$ & \\
\hline$\% \mathrm{POV}$ & $-0.006(0.000)$ & $-0.012(0.000)$ & $-0.001(0.000)$ & \\
\hline$\% \triangle P O P$ & $0.000(0.349)$ & $0.000(0.112)$ & $0.000(0.511)$ & \\
\hline Adj. R-sq. & 0.347 & 0.530 & 0.703 & \\
\hline \multicolumn{5}{|c|}{ Endogeneity Regression: "White Flight," 2010-2015 } \\
\hline DV: Change \%White & Score $=I S$ & Score $=A C O$ & Score $=$ Gini & Score $=x P x$ \\
\hline CONSTANT & Coeff. (p-val.) & Coeff. (p-val.) & Coeff. (p-val.) & Coeff. (p-val.) \\
\hline (Intercept) & $55.794(0.000)$ & $52.894(0.000)$ & $56.515(0.000)$ & $53.072(0.000)$ \\
\hline Change in Score & $-30.068(0.082)$ & $10.391(0.560)$ & $-27.033(0.075)$ & $3.114(0.814)$ \\
\hline Growth in Median Y & $0.109(0.550)$ & $0.160(0.396)$ & $0.051(0.786)$ & $0.123(0.545)$ \\
\hline$\%$ White & $-0.648(0.000)$ & $-0.614(0.000)$ & $-0.647(0.000)$ & $-0.608(0.000)$ \\
\hline$\%$ Black & $-0.532(0.000)$ & $-0.519(0.000)$ & $-0.529(0.000)$ & $-0.527(0.000)$ \\
\hline Adj. R-sq. & 0.628 & 0.613 & 0.629 & 0.612 \\
\hline
\end{tabular}

Note: Bold $=$ significant at 5 percent. P-values based on robust standard errors.

\subsection{Drivers of Variation: Regression Analysis}

Table 3 provides results for a baseline model that includes the poverty rate and population change since 1960. This latter variable might reflect the confluence of a number of socioeconomic trends (including economic growth and decline, immigration and outmigration, and national demographic trends), yet it is not significant in any of the regressions. Expanding this model to include specific socioeconomic variables, mentioned above, might both reveal significant contributors to the concentration of poverty, as well as increase model fit as measured by adjusted $R^{2}$.

In the bottom panel of Table 3, we also explore potential endogeneity, which might bias the results. We particularly examine the case where variables in the model might be simultaneously determined. Here, we test whether the concentration of poverty might in fact cause, rather than be affected by, one of our key explanatory variables. In this "White Flight" model, we theorize that the percentage change in the White share of the population (from 2010 to 2015) might decrease if poverty becomes more diffuse within a city. Additional explanatory variables include income growth (which might promote suburbanization or gentrification, leading to ambiguity in the expected coefficient sign), the initial percentage of White residents (expecting that larger losses can occur if the initial population is larger) and the percentage of Black residents (with the sign expected to be negative as well). We see in Table 3 that only these two latter variables have significant coefficients (of the expected sign). No measure of poverty concentration has a significant effect at the 5 percent significance level. Nevertheless, since problems can arise through other channels and cannot be avoided entirely (particularly without appropriate instruments), we advise that potential endogeneity be kept in mind when interpreting subsequent results.

We next model each of the four poverty concentration measures for our 74 cities, using the variables mentioned above, and selecting models based on both the underlying theory 
and the calculated correlations. The results of eight specifications are provided in Table 4. We consider the $I S$ score to be the most representative nonspatial index. Like the Gini coefficient, it increases in value as poverty concentration increases, but the $I S$ score is calculated using values for all block groups rather than five fairly wide quintiles. The $A C O$ score incorporates a spatial component and therefore is interesting as well. Models using the other two indices are also included in Table 4. The Gini results are very similar from those for the $I S$ score, but the $x P x$ score behaves differently from the rest. Not only does it increase with diffusion rather than with concentration, its other statistical properties (such as correlations) and regression coefficients differ from the other measures.

For all four concentration measures, increases in the poverty rate are associated with reduced poverty concentration, as was predicted by our theory and by the baseline regression model. In no specification are either of the dummy variables significant. Neither is the percentage of Black residents (although this variable is highly correlated with the poverty rate). Adjusted $R^{2}$ increases, in many cases significantly, above that of the baseline model in at least one expanded specification for each measure. While the four measures differ in terms of the influence of the other variables, certain key themes emerge.

First, the initial specification includes all explanatory variables together, even though some likely are collinear. This is evidenced by the fact that the poverty rate is insignificant in the $I S$ score model. Yet, when various correlated variables are dropped, the selection of significant variables remains unchanged. The only exception is the share of professional jobs in two cases.

Second, the IS score and Gini coefficients both show that larger White populations are associated with increased poverty concentrations, while larger Hispanic populations are associated with increased diffusion, even when controlling for other factors. A logical next step would be to examine the impact of immigration further. As expected, larger service sectors also lead to less concentrated poverty, but the share of professional jobs has little effect.

Finally, the $A C O$ score registers the fewest significant coefficients. It is the only one of the four measures to find increases in land area are linked to increases in the concentration of poverty (which would be expected if rural or suburban areas are added to an inner city), but its coefficient is very small and not significant at the 5 percent level. The $x P x$ score also behaves differently from the others. While the same variables are significant as was the case with the Gini coefficient, those for the ethnic variables are not opposite in sign. The $x P x$ score's low correlations with the others (particularly with the $I S$ score) is worthy of investigating, particularly if this variable is able to capture something that the others do not. While we note these differences among the measures, and stress that they cannot be considered to be identical to one another, future studies might uncover the causes and effects of this variation. We also stress again that potential endogeneity makes us wary of implying too much regarding causal relationships.

(c)Southern Regional Science Association 2019. 


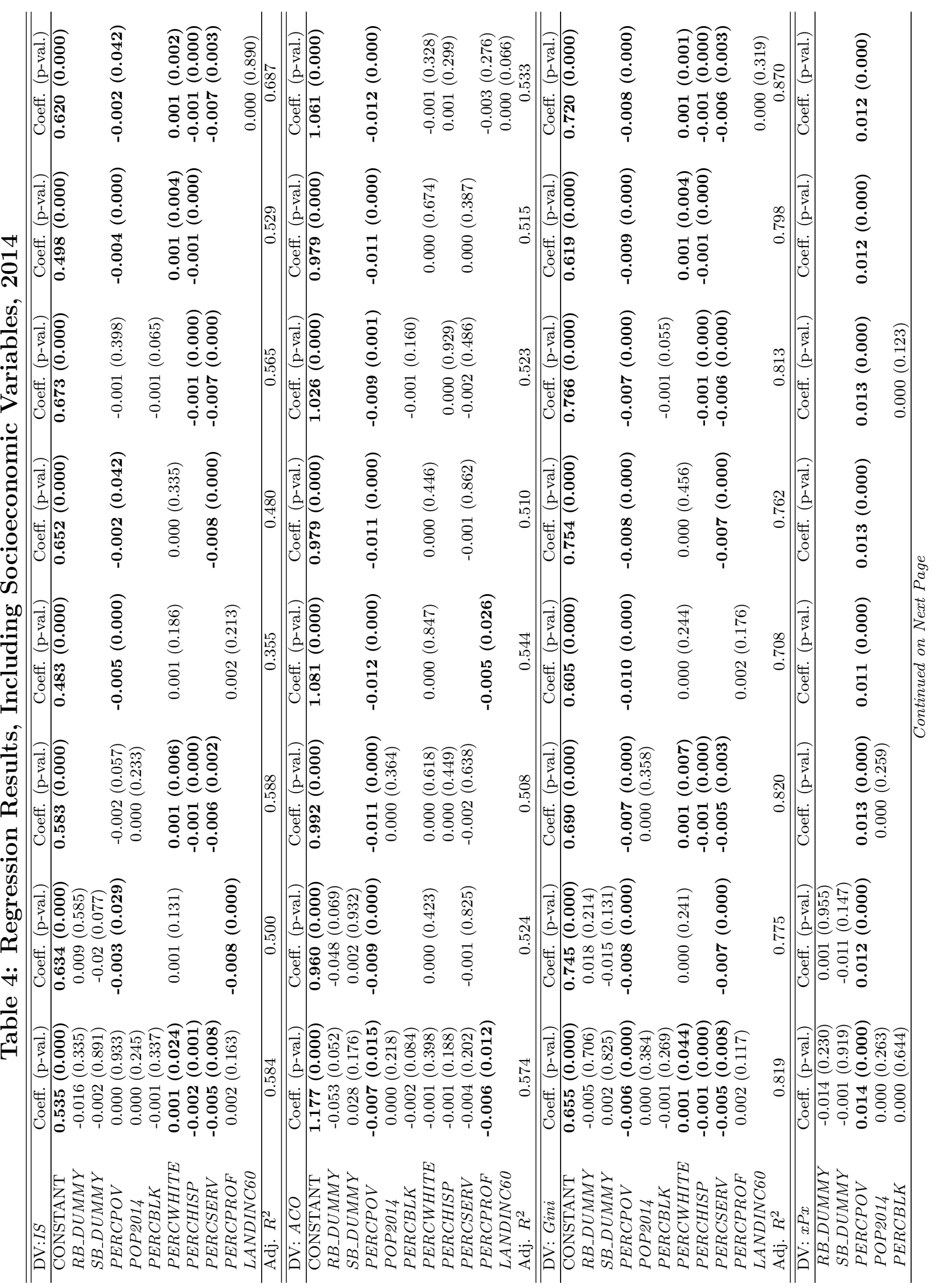

(C)Southern Regional Science Association 2019. 


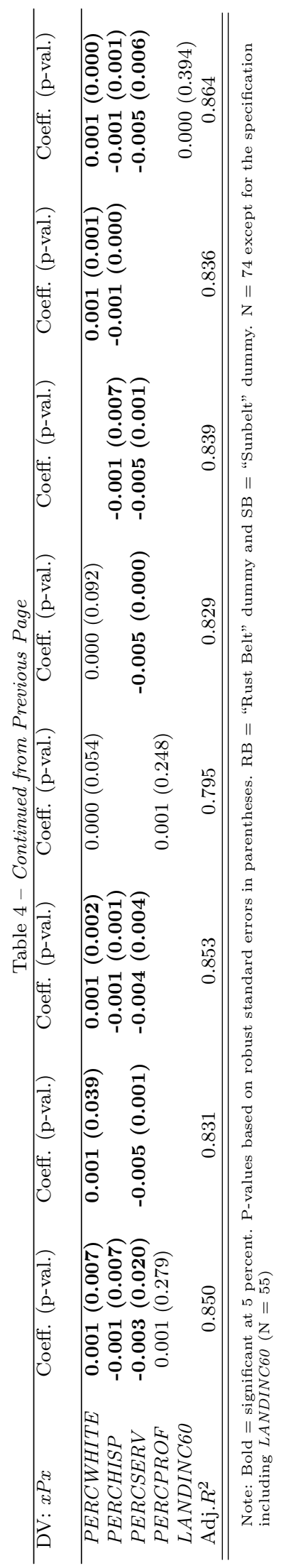

(c)Southern Regional Science Association 2019. 


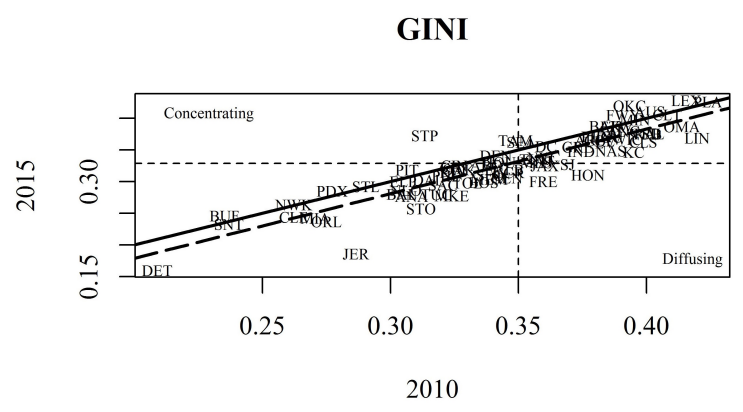

IS

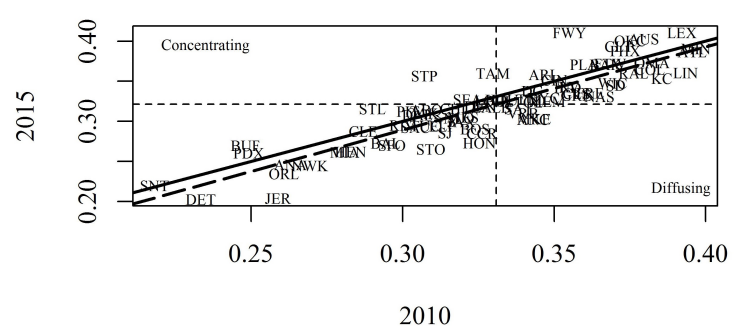

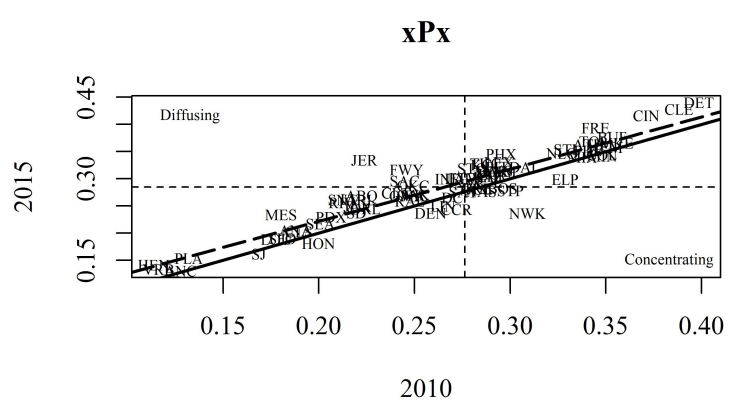

ACO



Figure 3: Spatial Measures of Poverty Concentration in 2015 vs. 2010

Low scores for Gini, IS, and $A C O$ or high scores for $x P x=$ "Diffuse" poverty (low concentration). High scores for Gini, IS, and $A C O$ or low scores for $x P x=$ "Concentrated" poverty. Increases in Gini, $I S$, and $A C O$ scores or decrease in $x P x=$ "Concentrating" (opposite $=$ "Diffusing"). Solid line in scatterplots $=45$-degree line representing 2015 values equaling 2010 values. Dashed line $=$ regression line. Horizontal and vertical dotted lines $=$ median values.

\subsection{Changes in Scores}

How has the concentration of poverty changed in recent years? We begin this investigation by plotting 2010 and 2015 tract-level scores for each measure in Figure 3. We also include a 45degree line to represent stable coefficient values over the two time periods, as well as bivariate regression lines. Three of the four regression lines have slopes that are not significantly different from one, but with a shifted intercept (which is significantly different from zero for the $x P x$ score) that represents an overall decrease in concentration between 2010 and 2015 . The $A C O$ score - the only one to include land area - has a higher intercept and a slightly lower slope, suggesting that these values became more "compressed" as low concentration scores rose and high scores fell. While there are similarities, as well as differences, among the four measures, we focus here on the $I S$ score and leave disparities in the behavior of the $A C O$ score to a future study. Table 2 shows the Spearman correlations among changes in these measures. Again, the Gini coefficient is highly correlated with the $I S$ score.

Table 5 provides calculated scores for all four tract-level measures, as well as classifications as "Concentrating" (increasing $I S$ score) and "Diffusing' (decreasing $I S$ score). In all, 23 cities show increased concentration, while 51 register increased diffusion of poverty. This result corresponds with the shift in intercept. 
Table 5: Calculated Concentration Scores

\begin{tabular}{|c|c|c|c|c|c|c|c|c|c|c|c|c|c|}
\hline & & 2010 & & & & 2015 & & & & $(\log )($ & hange & & \\
\hline CODE & Change_IS & Gini & $I S$ & $x P x$ & $A C O$ & Gini & $I S$ & $x P x$ & $A C O$ & Gini & $I S$ & $x P x$ & $A C O$ \\
\hline ABQ & Concentrating & 0.324 & 0.313 & 0.267 & 0.634 & 0.337 & 0.308 & 0.222 & 0.670 & 0.04 & -0.02 & -0.18 & 0.05 \\
\hline ANA & Diffusing & 0.277 & 0.246 & 0.205 & 0.782 & 0.308 & 0.263 & 0.188 & 0.782 & 0.11 & 0.07 & -0.09 & 0.00 \\
\hline ANC & Diffusing & 0.379 & 0.302 & 0.131 & 0.961 & 0.391 & 0.343 & 0.128 & 0.915 & 0.03 & 0.13 & -0.02 & -0.05 \\
\hline ARL & Concentrating & 0.366 & 0.359 & 0.262 & 0.717 & 0.378 & 0.346 & 0.222 & 0.697 & 0.03 & -0.04 & -0.17 & -0.03 \\
\hline ATL & Diffusing & 0.380 & 0.387 & 0.364 & 0.710 & 0.386 & 0.396 & 0.340 & 0.675 & 0.02 & 0.02 & -0.07 & -0.05 \\
\hline AUS & Concentrating & 0.410 & 0.403 & 0.314 & 0.837 & 0.401 & 0.380 & 0.293 & 0.795 & -0.02 & -0.06 & -0.07 & -0.05 \\
\hline BAK & Concentrating & 0.388 & 0.371 & 0.314 & 0.829 & 0.384 & 0.367 & 0.291 & 0.805 & -0.01 & -0.01 & -0.08 & -0.03 \\
\hline BAL & Diffusing & 0.281 & 0.273 & 0.304 & 0.715 & 0.304 & 0.294 & 0.289 & 0.682 & 0.08 & 0.07 & -0.05 & -0.05 \\
\hline BOS & Diffusing & 0.299 & 0.290 & 0.283 & 0.725 & 0.336 & 0.324 & 0.296 & 0.728 & 0.12 & 0.11 & 0.04 & 0.00 \\
\hline BUF & Concentrating & 0.246 & 0.270 & 0.376 & 0.594 & 0.235 & 0.248 & 0.353 & 0.580 & -0.05 & -0.08 & -0.06 & -0.03 \\
\hline CCR & Diffusing & 0.315 & 0.285 & 0.244 & 0.799 & 0.346 & 0.326 & 0.272 & 0.857 & 0.09 & 0.13 & 0.11 & 0.07 \\
\hline CHI & Diffusing & 0.321 & 0.316 & 0.305 & 0.687 & 0.324 & 0.317 & 0.289 & 0.664 & 0.01 & 0.00 & -0.05 & -0.03 \\
\hline CIN & Concentrating & 0.325 & 0.352 & 0.416 & 0.583 & 0.325 & 0.350 & 0.371 & 0.570 & 0.00 & -0.01 & -0.11 & -0.02 \\
\hline CLE & Concentrating & 0.244 & 0.288 & 0.428 & 0.617 & 0.262 & 0.287 & 0.388 & 0.663 & 0.07 & 0.00 & -0.10 & 0.07 \\
\hline CLS & Diffusing & 0.363 & 0.335 & 0.203 & 0.814 & 0.399 & 0.357 & 0.190 & 0.803 & 0.09 & 0.06 & -0.07 & -0.01 \\
\hline CLT & Concentrating & 0.406 & 0.394 & 0.274 & 0.689 & 0.408 & 0.371 & 0.240 & 0.685 & 0.00 & -0.06 & -0.13 & -0.01 \\
\hline COL & Diffusing & 0.364 & 0.365 & 0.344 & 0.787 & 0.382 & 0.382 & 0.348 & 0.767 & 0.05 & 0.05 & 0.01 & -0.03 \\
\hline DAL & Concentrating & 0.303 & 0.308 & 0.322 & 0.649 & 0.315 & 0.305 & 0.308 & 0.575 & 0.04 & -0.01 & -0.04 & -0.12 \\
\hline $\mathrm{DC}$ & Diffusing & 0.356 & 0.338 & 0.266 & 0.744 & 0.361 & 0.343 & 0.270 & 0.723 & 0.01 & 0.01 & 0.01 & -0.03 \\
\hline DEN & Diffusing & 0.341 & 0.319 & 0.237 & 0.859 & 0.341 & 0.326 & 0.258 & 0.860 & 0.00 & 0.02 & 0.08 & 0.00 \\
\hline DET & Diffusing & 0.160 & 0.203 & 0.440 & 0.515 & 0.209 & 0.233 & 0.399 & 0.505 & 0.27 & 0.14 & -0.10 & -0.02 \\
\hline ELP & Diffusing & 0.300 & 0.294 & 0.299 & 0.750 & 0.305 & 0.313 & 0.329 & 0.727 & 0.02 & 0.06 & 0.10 & -0.03 \\
\hline FRE & Diffusing & 0.300 & 0.336 & 0.394 & 0.694 & 0.360 & 0.362 & 0.345 & 0.691 & 0.18 & 0.07 & -0.13 & 0.00 \\
\hline FTW & Concentrating & 0.387 & 0.372 & 0.301 & 0.871 & 0.388 & 0.368 & 0.276 & 0.874 & 0.00 & -0.01 & -0.09 & 0.00 \\
\hline FWY & Concentrating & 0.405 & 0.411 & 0.317 & 0.718 & 0.391 & 0.355 & 0.246 & 0.682 & -0.04 & -0.15 & -0.25 & -0.05 \\
\hline GRE & Diffusing & 0.355 & 0.333 & 0.282 & 0.776 & 0.373 & 0.357 & 0.282 & 0.763 & 0.05 & 0.07 & 0.00 & -0.02 \\
\hline HEN & Diffu & 0.306 & 0.262 & 0.142 & 0.848 & 0.345 & 0.283 & 0.114 & 0.855 & 0.12 & 0.08 & -0.22 & 0.01 \\
\hline $\mathrm{HON}$ & Dif & 0.311 & 0.273 & 0.181 & 0.877 & 0.377 & 0.325 & 0.200 & 0.863 & 0.19 & 0.17 & 0.10 & -0.02 \\
\hline $\mathrm{HOU}$ & Diffu & 0.330 & 0.327 & 0.309 & 0.760 & 0.342 & 0.333 & 0.292 & 0.759 & 0.04 & 0.02 & -0.06 & 0.00 \\
\hline IND & Diffusing & 0.348 & 0.342 & 0.300 & 0.837 & 0.374 & 0.354 & 0.268 & 0.814 & 0.07 & 0.03 & -0.11 & -0.03 \\
\hline JAX & Diffusing & 0.325 & 0.300 & 0.249 & 0.861 & 0.360 & 0.319 & 0.220 & 0.835 & 0.10 & 0.06 & -0.12 & -0.03 \\
\hline JER & Diffusing & 0.186 & 0.204 & 0.334 & 0.761 & 0.286 & 0.259 & 0.224 & 0.574 & 0.43 & 0.24 & -0.40 & -0.28 \\
\hline $\mathrm{KC}$ & Diffusing & 0.346 & 0.354 & 0.326 & 0.808 & 0.395 & 0.386 & 0.285 & 0.778 & 0.13 & 0.09 & -0.13 & -0.04 \\
\hline LAX & Diffusing & 0.319 & 0.318 & 0.301 & 0.805 & 0.344 & 0.329 & 0.276 & 0.794 & 0.08 & 0.03 & -0.09 & -0.01 \\
\hline LEX & Concentrating & 0.428 & 0.411 & 0.331 & 0.882 & 0.416 & 0.392 & 0.294 & 0.864 & -0.03 & -0.05 & -0.12 & -0.02 \\
\hline LIN & Diffusing & 0.369 & 0.360 & 0.250 & 0.687 & 0.420 & 0.393 & 0.265 & 0.701 & 0.13 & 0.09 & 0.06 & 0.02 \\
\hline $\mathrm{LOU}$ & Diffusing & 0.371 & 0.326 & 0.189 & 0.828 & 0.385 & 0.329 & 0.178 & 0.823 & 0.04 & 0.01 & -0.06 & -0.01 \\
\hline LV & Diffu & 0.362 & 0.343 & 0.262 & 0.647 & 0.384 & 0.355 & 0.217 & 0.764 & 0.06 & 0.03 & -0.19 & 0.17 \\
\hline MEM & Diffusing & 0.304 & 0.325 & 0.358 & 0.668 & 0.339 & 0.348 & 0.349 & 0.651 & 0.11 & 0.07 & -0.03 & -0.03 \\
\hline MES & Diffusing & 0.330 & 0.305 & 0.234 & 0.793 & 0.357 & 0.320 & 0.180 & 0.792 & 0.08 & 0.05 & -0.26 & 0.00 \\
\hline MIA & Diffusing & 0.243 & 0.262 & 0.340 & 0.542 & 0.271 & 0.281 & 0.338 & 0.527 & 0.11 & 0.07 & -0.01 & -0.03 \\
\hline MIN & Diffusing & 0.398 & 0.391 & 0.341 & 0.679 & 0.396 & 0.397 & 0.348 & 0.642 & -0.01 & 0.02 & 0.02 & -0.06 \\
\hline MKE & $\lg$ & 0.278 & 0.303 & 0.366 & 0.751 & 0.324 & 0.343 & 0.356 & 0.716 & 0.15 & 0.12 & -0.03 & -0.05 \\
\hline NAS & Diffusing & 0.349 & 0.331 & 0.277 & 0.852 & 0.386 & 0.365 & 0.285 & 0.815 & 0.10 & 0.10 & 0.03 & -0.05 \\
\hline NLO & Diffusing & 0.286 & 0.304 & 0.347 & 0.700 & 0.306 & 0.319 & 0.327 & 0.613 & 0.07 & 0.05 & -0.06 & -0.13 \\
\hline NWK & Diffusing & 0.263 & 0.245 & 0.236 & 0.607 & 0.262 & 0.269 & 0.309 & 0.712 & 0.00 & 0.09 & 0.27 & 0.16 \\
\hline NYC & Diffusing & 0.338 & 0.329 & 0.290 & 0.837 & 0.360 & 0.346 & 0.279 & 0.822 & 0.06 & 0.05 & -0.04 & -0.02 \\
\hline OAK & Concentrating & 0.319 & 0.310 & 0.270 & 0.806 & 0.327 & 0.306 & 0.250 & 0.790 & 0.02 & -0.01 & -0.08 & -0.02 \\
\hline $\mathrm{OKC}$ & Concentrating & 0.420 & 0.401 & 0.287 & 0.900 & 0.393 & 0.375 & 0.249 & 0.907 & -0.07 & -0.07 & -0.14 & 0.01 \\
\hline OMA & Diffusing & 0.387 & 0.373 & 0.269 & 0.709 & 0.414 & 0.382 & 0.246 & 0.709 & 0.07 & 0.02 & -0.09 & 0.00 \\
\hline ORL & Diffusing & 0.237 & 0.235 & 0.245 & 0.826 & 0.275 & 0.261 & 0.224 & 0.829 & 0.15 & 0.10 & -0.09 & 0.00 \\
\hline PDX & Concentrating & 0.285 & 0.260 & 0.230 & 0.827 & 0.277 & 0.249 & 0.206 & 0.791 & -0.03 & -0.04 & -0.11 & -0.05 \\
\hline PHL & Diffusing & 0.309 & 0.325 & 0.352 & 0.698 & 0.322 & 0.332 & 0.341 & 0.683 & 0.04 & 0.02 & -0.03 & -0.02 \\
\hline PHX & Concentrating & 0.371 & 0.388 & 0.346 & 0.834 & 0.380 & 0.374 & 0.295 & 0.821 & 0.02 & -0.04 & -0.16 & -0.02 \\
\hline PIT & Concentrating & 0.319 & 0.312 & 0.322 & 0.647 & 0.306 & 0.302 & 0.293 & 0.662 & -0.04 & -0.03 & -0.09 & 0.02 \\
\hline PLA & Concentrating & 0.426 & 0.371 & 0.154 & 0.677 & 0.424 & 0.360 & 0.132 & 0.690 & 0.00 & -0.03 & -0.15 & 0.02 \\
\hline RAL & Diffusing & 0.376 & 0.360 & 0.259 & 0.690 & 0.401 & 0.376 & 0.248 & 0.683 & 0.06 & 0.04 & -0.04 & -0.01 \\
\hline RIV & Diffusing & 0.315 & 0.295 & 0.256 & 0.669 & 0.324 & 0.300 & 0.212 & 0.697 & 0.03 & 0.02 & -0.19 & 0.04 \\
\hline SAC & Diffusing & 0.295 & 0.293 & 0.296 & 0.616 & 0.321 & 0.304 & 0.245 & 0.578 & 0.08 & 0.04 & -0.19 & -0.06 \\
\hline SAT & Diffusing & 0.333 & 0.316 & 0.276 & 0.762 & 0.358 & 0.338 & 0.276 & 0.763 & 0.07 & 0.07 & 0.00 & 0.00 \\
\hline $\mathrm{SD}$ & Diffusing & 0.376 & 0.345 & 0.237 & 0.871 & 0.402 & 0.370 & 0.220 & 0.878 & 0.07 & 0.07 & -0.07 & 0.01 \\
\hline SEA & Concentrating & 0.362 & 0.327 & 0.217 & 0.696 & 0.351 & 0.321 & 0.201 & 0.690 & -0.03 & -0.02 & -0.08 & -0.01 \\
\hline
\end{tabular}
Continued on next page 
Table 5 - Continued from previous page

\begin{tabular}{|c|c|c|c|c|c|c|c|c|c|c|c|c|c|}
\hline & \multicolumn{4}{|c|}{2010} & \multicolumn{3}{|c|}{2015} & \multicolumn{6}{|c|}{ (log) Change } \\
\hline CODE & Change_IS & Gini & $I S$ & $x P x$ & $A C O$ & Gini & $I S$ & $x P x$ & $A C O$ & Gini & $I S$ & $x P x$ & $A C O$ \\
\hline SFO & Diffusing & 0.310 & 0.270 & 0.190 & 0.751 & 0.339 & 0.296 & 0.181 & 0.724 & 0.09 & 0.09 & -0.05 & -0.04 \\
\hline SJ & Diffusing & 0.327 & 0.286 & 0.162 & 0.832 & 0.369 & 0.314 & 0.169 & 0.815 & 0.12 & 0.09 & 0.04 & -0.02 \\
\hline SNT & Concentrating & 0.233 & 0.220 & 0.261 & 0.622 & 0.237 & 0.218 & 0.212 & 0.604 & 0.02 & -0.01 & -0.21 & -0.03 \\
\hline STL & Concentrating & 0.292 & 0.316 & 0.354 & 0.645 & 0.290 & 0.290 & 0.330 & 0.639 & -0.01 & -0.09 & -0.07 & -0.01 \\
\hline STO & Diffusing & 0.257 & 0.265 & 0.319 & 0.729 & 0.312 & 0.309 & 0.280 & 0.710 & 0.19 & 0.15 & -0.13 & -0.03 \\
\hline STP & Concentrating & 0.373 & 0.357 & 0.278 & 0.641 & 0.313 & 0.307 & 0.300 & 0.864 & -0.18 & -0.15 & 0.08 & 0.30 \\
\hline TAM & Concentrating & 0.366 & 0.360 & 0.314 & 0.747 & 0.349 & 0.330 & 0.294 & 0.790 & -0.05 & -0.09 & -0.07 & 0.06 \\
\hline TOL & Diffusing & 0.298 & 0.324 & 0.369 & 0.683 & 0.330 & 0.342 & 0.344 & 0.672 & 0.10 & 0.05 & -0.07 & -0.02 \\
\hline TUC & Diffusing & 0.280 & 0.294 & 0.328 & 0.755 & 0.318 & 0.308 & 0.287 & 0.699 & 0.13 & 0.05 & -0.13 & -0.08 \\
\hline TUL & Diffusing & 0.335 & 0.327 & 0.281 & 0.708 & 0.356 & 0.342 & 0.283 & 0.736 & 0.06 & 0.04 & 0.01 & 0.04 \\
\hline VRB & Diffusing & 0.375 & 0.310 & 0.134 & 0.913 & 0.400 & 0.340 & 0.116 & 0.902 & 0.06 & 0.09 & -0.14 & -0.01 \\
\hline WIC & Diffusing & 0.367 & 0.348 & 0.269 & 0.828 & 0.392 & 0.369 & 0.250 & 0.793 & 0.07 & 0.06 & -0.07 & -0.04 \\
\hline
\end{tabular}

Note: Denver, CO includes Aurora; Los Angeles, CA includes Long Beach; San Diego, CA includes Chula Vista. These are contiguous cities that share a cluster of poverty and are therefore treated as a single unit.

To examine possible drivers of changes in poverty concentration over this period, we plot log changes in $I S$ against a selection of economic and demographic variables in Figure 4. These include median income growth, population change, and changes in poverty rates (from 2010 to 2015), as well as the White and Hispanic shares of the population for each city. While all intercepts are statistically significant, the only significant slope coefficients are on the percentage of the White population (2010) and growth in the Hispanic population (2010-2015). Cities that are whiter in 2010 have seen increased poverty concentration, while those with increasing shares of Hispanic residents appear to have "diffusing" poverty.

The outliers from the plot of 2015 and 2010 scores depicted in Figure 3, including Ft. Wayne, St. Paul, Jersey City, and Corpus Christi, stand out as well. These include two industrial towns (one of which is located in the Rust Belt and the other in the Sunbelt), as well as a relatively well-off state capital and a New York suburb with a large professional class. This diversity in socioeconomic characteristics suggests that idiosyncratic factors be investigated for these and other cities when explaining changes in poverty concentrations, in addition to other explanatory variables. Further investigation is necessary, therefore, to uncover the underlying economic forces behind the concentration of poverty and whether this is a general nationwide trend.

Perhaps these ethnic factors do indeed explain the concentration and diffusion of poverty and are clearly worthy of additional study. It is important to note, however, that the "Rust Belt" and "Sunbelt" groupings hold far less for changes in scores than they do for the 2014 scores. This suggests that the distribution of poverty is a result of past, rather than recent, factors and that changes since 1960 might be a more appropriate time frame for further study.

\section{CONCLUSION}

Growing economic inequality in the U.S. has led to increasing segregation of the poor from the wealthy and has resulted in metropolitan areas that contain both areas of high income and pockets of poverty. A number of studies have calculated measures of this inequality and have tried to explain the causes of the variation. Since many of these have only examined 


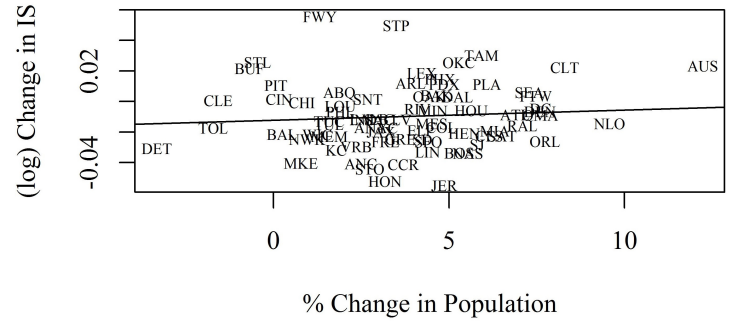

(a) OLS Estimate: $\mathrm{Y}=\mathbf{- 0 . 0 1 1}+0.0003 \mathrm{X}$

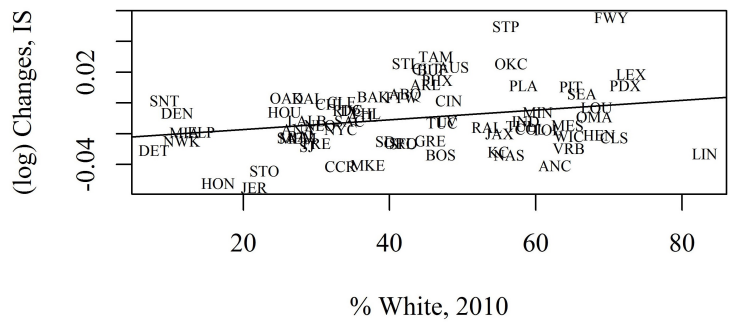

(c) OLS Estimate: $\mathrm{Y}=\mathbf{- 0 . 0 2 3}+\mathbf{0 . 0 0 0 3 X}$

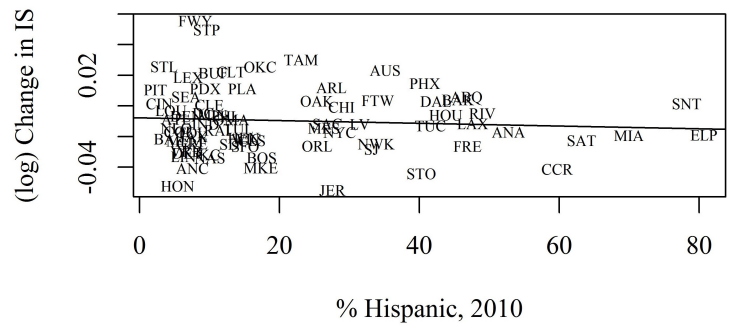

(e) OLS Estimate: $\mathrm{Y}=-0.0007+0.0000 \mathrm{X}$

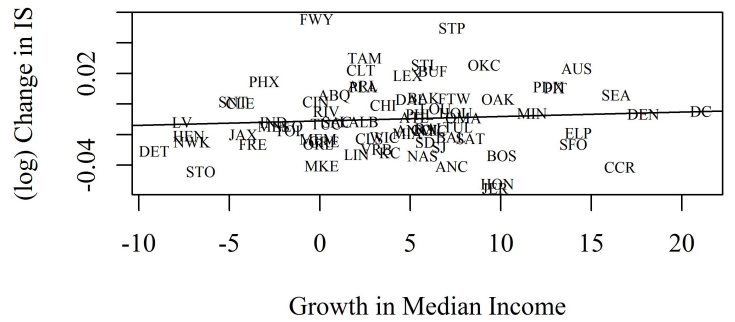

(b) OLS Estimate: $\mathrm{Y}=\mathbf{- 0 . 0 2 3}+0.0007 \mathrm{X}$

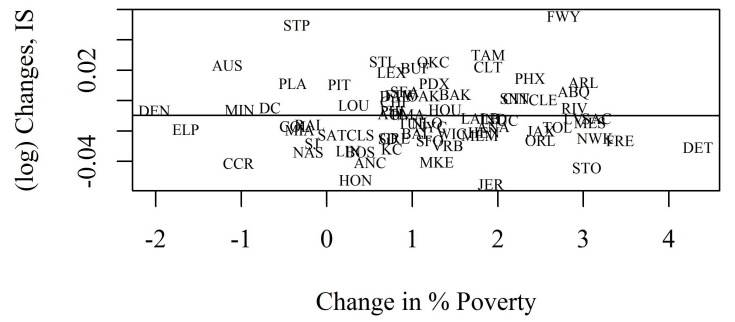

(d) OLS Estimate: $\mathrm{Y}=\mathbf{- 0 . 0 0 9 7}+0.000 \mathrm{X}$

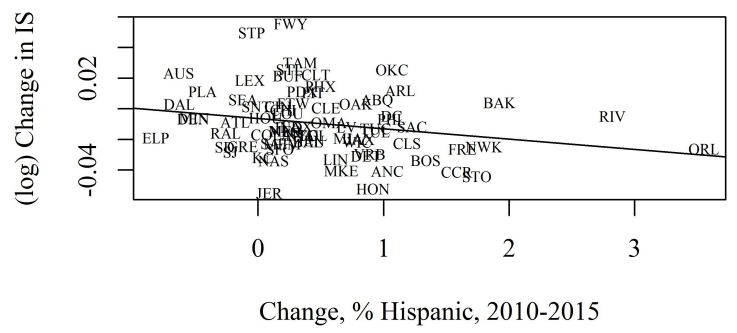

(f) OLS Estimate: $\mathrm{Y}=\mathbf{- 0 . 0 0 6 2} \mathbf{0 . 0 0 6 7 X}$

Figure 4: Changes in $I S$ Scores Versus Changes in Income and Population

Bold $=$ significant at 5 percent level.

metropolitan areas, which include both high-income suburbs and poor central cities, the distribution of poverty within the cities themselves is often overlooked. Detroit, for example, is located in one of the most segregated metro areas, but is unique in its ubiquity of poverty within the city limits. Often used as a cautionary tale or as a test case for development strategy, Detroit is a common benchmark against which other cities are compared. In this paper, we show that Detroit is a unique case, with only Cleveland and a few other "Rust Belt" cities even remotely comparable as high-poverty, low-concentration central cities.

Examining U.S. Census block groups for 74 cities in the year 2014, we calculate four measures of the dispersion of household poverty. We find that high poverty diffusion corresponds to high poverty rates, supporting a hypothetical model of poverty diffusion developed here. We isolate a "Rust Belt" grouping of cities, as well as a group of exceptionally low-poverty, high-concentration cities in the U.S. South and West (of which Plano, Texas serves as a model). We also find a set of "Sunbelt" cities with average poverty rates, but unexpectedly diffuse poverty, as well as some regional metropolitan centers with unexpectedly concentrated poverty. 
To explain these differences, we conduct a number of regression analyses, finding that poverty concentration is best explained by the poverty rate itself, with racial and ethnic factors also playing a role in many cases. Higher percentages of White residents are associated with higher poverty concentrations, while greater shares Hispanic residents might lead to more diffusion. The share of service employment might also be related to poverty diffusion as well. Other variables, such as population change since 1960, the share of professional employment, the growth in city land area, or the percent of Black residents, appear to have no effect on the distribution of poverty in 2014. But, because of potential endogeneity in these variables, a true causal relationship might be difficult to uncover. An examination of tract-level changes in scores from 2010 to 2015 shows that while poverty has generally become less concentrated during this period, economic factors provide little explanation in the variance among cities. Only demographic characteristics have any explanatory power, but this is limited.

These results open up three avenues for future research. The first is to continue to compare differences in concentration measures. The second would be to further examine possible explanatory variables that were introduced there, particularly the role of immigration. The third is to evaluate outlier cities from the current analysis, both high-and low-income, as special cases worthy of further study.

The results found here not only have implications for examining and classifying different types of U.S. cities, but they can also be used by policymakers to address the spatial distribution of poverty. Understanding Detroit's unique characteristics might help leaders in other cities avoid a "one size fits all" approach in applying solutions. Economic programs might instead be borrowed from cities with a similar profile and cities with lower poverty concentrations have more resources with which to help their poorest neighborhoods. Adjacent suburbs, in addition, might be wary of poverty "diffusion" along their urban borders and wish to allocate resources effectively. Most importantly, this study shows the differences among inner cities themselves, and the importance of these cities, rather than simply as a part of the urban-suburban divide.

\section{REFERENCES}

Adelman, Robert M. and Charles Jaret. (1999) "Poverty, Race, and U.S. Metropolitan Social and Economic Structure," Journal of Urban Affairs, 21(1), 35-56.

Ades, Josefina and Anne-Marie Apparicio, Philippeand Sèguin. (2012) "Are New Patterns of Low-Income Distribution Emerging in Canadian Metropolitan Areas?," The Canadian Geographer/Le Gèographe canadien, 56(3), 339-361.

Aliprantis, Dionissi, Kyle Fee, and Nelson Oliver. (2013) The Concentration of Poverty within Metropolitan Areas. Last accessed November $2019 \quad$ at https://www.clevelandfed.org/en/newsroom-and-events/ publications/economic-commentary/2013-economic-commentaries/

ec-201301-the-concentration-of-poverty-within-metropolitan-areas.aspx.

Cook, Thomas and Sarah Marchant. (2006) "The Changing Intrametropolitan Location of High-Poverty Neighbourhoods in the U.S., 1990-2000," Urban Studies, 43(11), 1971-1989.

(C)Southern Regional Science Association 2019. 
Dawkins, Casey J. (2004) "Measuring the Spatial Pattern of Residential Segregation," Urban Studies, 41(4), 833-851.

Dwyer, Rachel E. (2012) "Contained Dispersal: The Deconcentration of Poverty in US Metropolitan Areas in the 1990s," City \& Community, 11(3), 309-331.

Howell, Aaron J. and Jeffrey M. Timberlake. (2014) "Racial and Ethnic Trends in the Suburbanization of Poverty in U.S. Metropolitan Areas, 1980-2010," Journal of Urban Affairs, 6(1), 79-98.

Kavanagh, Leo, Duncan Lee, and Gwilym Pryce. (2016) "Is Poverty Decentralizing? Quantifying Uncertainty in the Decentralization of Urban Poverty," Annals of the American Association of Geographers, 106(6), 1286-1298.

Kneebone, Elizabeth, Carey Nadeau, and Alan Berube. (2011) "The Re-Emergence of Concentrated Poverty: Metropolitan Trends in the 2000s," Metropolitan Policy Program at Brookings.

Leventhal, Tama and Jeanne Brooks-Gunn. (2003) "Moving to Opportunity: An Experimental Study of Neighborhood Effects on Mental Health," American Journal of Public Health, 93(9), 1576-1582.

Madden, Janice Fadding. (1996) "Changes in the Distribution of Poverty across and within the US Metropolitan Areas, 1979-89," Urban Studies, 33(9), 1581-1600.

Madden, Janice Fadding. (2003) "The Changing Spatial Concentration of Income and Poverty among Suburbs of Large US Metropolitan Areas," Urban Studies, 40(3), 481503.

Massey, Douglas S. and Nancy A. Denton. (1988) "The Dimensions of Residential Segregation," Social Forces, 67(2), 281-315.

Rusk, David. (2013) Cities Without Suburbs: A Census 2010 Perspective. Johns Hopkins University Press, Baltimore.

Sharkey, Patrick. (2008) "The Intergenerational Transmission of Context," American Journal of Sociology, 113(4), 931-969.

Sharkey, Patrick. (2012) "Residential Mobility and the Reproduction of Unequal Neighborhoods," Cityscape: A Journal of Policy Development and Research, 14(3), 9-32.

Small, Mario Luis and Katherine Newman. (2001) "Urban Poverty After the Truly Disadvantaged: The Rediscovery of the Family, the Neighborhood, and Culture," Annual Review of Sociology, 27, 23-45.

Weinberg, Daniel H. (2011) U.S. Neighborhood Income Inequality in the 20052009 Period: American Community Survey eports. Available online in November 2019 at https://www.census.gov/newsroom/releases/archives/american_community_ survey_acs/cb11-tps39.html.

(C)Southern Regional Science Association 2019. 